$\xi=1$ 圈

\title{
Parametric study of sliding mode fracture in structural plain cement concrete for various sizes of beams
}

\author{
Bhavanichowdary $\mathbf{T}^{1}$ *, S.Padmaja ${ }^{2}$, M.Saritha ${ }^{2}$, M. Vinod Kumar ${ }^{2}$ \\ ${ }^{1}$ Assistant Professor,Vardhaman College of Engineering, Department of Civil, Hyderabad-500018,Telangana. \\ Research Scholar Koneru Lakshmana Education Foundation, Department of Civil, Guntur-522502, AP. \\ ${ }^{2}$ Assistant Professor,Vemu Institute ofTechnology, Department of Civil,P.Kothakota-517112, AP. \\ *Corresponding author E-mail:bhavanitalasila@vardhaman.org
}

\begin{abstract}
Fracture mechanics a part of solid mechanics deals with the crack initiation and propagation under certain loading conditions, as we know at ultimate load, the maximum shear stress is relatively larger than the shear strength in existence of compressive stress, which eventually results in shear failure. Under this criteria, failure is mode II which we can state that as the sliding mode. In this current research paper, an experimental investigation is carried out to study the behavior of plain cement concrete beams subjected to four point loading. Three different sizes of beams with Doubly Centered Notch (DCN) are used to examine the consequence of stress intensity factor and fracture energy with diversified notch depth ratios with a constant position of the notch from a center of the beam.
\end{abstract}

Keywords: Doubly Centered Notch; Fracture Mechanics; Mode II Fracture; Notch Depth Ratios; Stress Intensity Factor.

\section{Introduction}

Fracture mechanics deals with the study of the behavior of progressive crack extension in structures subjected to an applied load. Fracture mechanics is all about cracks, stress fields around cracks, stress intensity factors at cracks, failures due to cracks, growth rates of cracks, etc.

This research on fracture came into existence in the 1920's by Griffith analysis, which is based on energy. In 1983, the National Bureau Of Standards (now the National Institute for science and Technology) and Battelle Memorial Institute estimated the costs for failure due to fracture is found to be $\$ 119$ billion dollars per year in 1982. Criteria for the cost are important but the loss of human life and injuries are considerably more. Failure can occur due tomany reasons, including uncertainties in the loading conditions or environment impacts, defects in the materials used, deficient in design, and faults in construction or maintenance. Fracture design has got it's prominence in the current trend. This module will provide an introduction to a vital aspect of this field since without an understanding of the kind of fracture the methods in stress analysis discussed previously would be minute use. A fatal number of engineering disasters are related directly to this phenomenon, and engineers involved in designing must be aware of all the procedures which are currently available to safeguard against brittle fracture. The central obscurity in beginning against fracture in high strength materials is that the presence of cracks can alter the local stresses to such an extent that the elastic stress analysis done so carefully by the designers is unsatisfactory.

\subsection{Historical aspects of fracture mechanics}

In a long run, we constantly had an idea about the significance role of a crack or a notch. In process of felling a tree, we would make a notch with an axe at its trunk and then pull it down with a rope. Similarly while breaking a stick we would make a small notch with a knife before bending it. Swords were made by folding a thin metal sheet at the center line and then thrashing it to make it thin again so that it could be further folded. So, a sword would have number layers. If a crack progress in one of the layers, it is not intended to grow further to layers, thus making the sword very tough enough. Irwin's findings mainly reflect the brittle or less ductile materials. The analysis was conventional for most engineering materials which are generally ductile. Other criteria's, like Crack Tip Opening Displacement by Wells in 1961 and Jintegral by Rice in 1968, were developed to account for the sizeable plastic zone at the crack tip in ductile materials.

Fracture mechanics is now applied extensively to notable fields like nuclear engineering, piping, space ships, rockets, offshore structures etc. Significant components in the nuclear power plants are made up of very tough materials; but they too have failed terribly once in a while.

\subsection{Fracture mechanics}

Materials such as ceramics, rocks, glasses and concretes behave as brittle and fragile materials the crack initiation is determined by using the linear elastic stress field around the crack tip. This assumption belongs to Linear Elastic Fracture Mechanics (LEFM) assumption. This assumption is valid, when plastic deformation around the crack is insignificant.

\subsection{Linear elastic fracture mechanics (LEFM)}

First assumption is that the material is isotropic and linear elastic. Based on the assumption, the stress field near the crack tip is computed by using the theory of elasticity. When the stresses near the crack tip exceed the material fracture toughness, the crack will escalate. In Linear Elastic Fracture Mechanics, most formulas are derived for either in-plane stresses or plane strains, associated with 
the three fundamentalmodes of loadings on a cracked body: opening, sliding and tearing. Again, LEFM is valid only when the inelastic deformation is small when compared to the size of the crack, what we typically named it as small-scale yielding. If large zones of plastic deformation develop before the crack grows, Elastic Plastic Fracture Mechanics (EPFM) must be used.

\subsubsection{Micro crack shielding}

Randomly oriented micro cracks occur at faults ahead of the crack tip. The micro-cracking is caused by the excessive stress concentration near the crack tip (Shah et al. 1995). The development of micro-cracks releases energy, which increases the amount of energy required to form unpredictable cracks (Anderson 2005).

\subsubsection{Crack deflection}

This occurs when enclosure (i.e., aggregates or fibers) is tough enough to avert the path of least resistance around the inclusion (Shah et al.1995).

\subsubsection{Crack bridging}

If an insertion is bonded to the concrete at both cracks faces the inclusion is capable to transfer stress across cracks (Shah et al 1995). It has been affirmed that fiber bridging is the most competent toughening mechanism for brittle materials (Anderson 2005).

\subsubsection{Surface friction}

Surface intermingle can cause energy dissipation due to friction between fracture surfaces (Shah et al. 1995).

\subsubsection{Crack tip blunting}

This commonly occurs when a crack arrive a void (Shah et al. 1995). This is a form of crack arrest which occurs when the energy required to produce a crack is lacking to overcome the materials resistance to fracture (Broek 1986).

\subsubsection{Crack branching}

Crack branching in concrete occurs due to heterogeneity of the material (Shah et al.1995). In an ideal situation the bifurcation of crack will occur, theoretically, when the fracture energy is twice that of the energy to defend against fracture (Broek 1986). These toughening mechanisms are all sources of inconsistency in the fracture behavior of concrete and may explain the basis of size effect (Shah et al. 1995).

\section{Experimental study}

The main ingredients used were cement, fine aggregate, coarse aggregate, water, and steel plates. Ordinary Portland cement of 53 grades conforming to IS: $12269-1987$ was used for t study. River sand passing through $4.75 \mathrm{~mm}$ sieve and conforming to grading zone II of IS: 383-1970 was used as the fine aggregates. Crushed granite stone with a maximum size of $20 \mathrm{~mm}$ was used as the coarse aggregate. Steel plates of $2 \mathrm{~mm}$ mean thickness and 22.5, $30,37.5,45,60,75,90,120,150,180 \mathrm{~mm}$ in width were used at $\mathrm{a} / \mathrm{w}$ ratios of $0.3,0.4,0.5,0.6$.Potablewater supplied by the college was used in the work.

\subsection{Mix design}

The normal strength concrete mix M30 was proportioned as per Indian Standard for a target mean strength $30 \mathrm{MPa}$. After various trial mixes, the optimum mix proportion was selected as $0.45: 1: 1.562: 2.902$ with cement content of $405.81 \mathrm{~kg} / \mathrm{m}^{3}$. The different constituents in the order of water, cement, fine aggregate, coarse aggregate were proportioned as 183.0:406.81:635.4:1180.56 for making $1 \mathrm{~m}^{3}$ of mix. The steel plates were prepared with a/wratios. The plates were placed at one-third of the length of the beam. Age curing is done in following [7], [14], [28] and [56] days.

Table 1: Details of Materials for 1 Cubic Meter of Concrete

\begin{tabular}{llllll}
\hline $\begin{array}{l}\text { Grade } \\
\text { of } \\
\text { concrete }\end{array}$ & Mix Proportion & $\begin{array}{l}\text { Water } \\
\text { wt } \\
(\mathrm{kg})\end{array}$ & $\begin{array}{l}\text { Cement } \\
\text { wt }(\mathrm{kg})\end{array}$ & $\begin{array}{l}\text { Weight } \\
\text { of FA } \\
(\mathrm{kg})\end{array}$ & $\begin{array}{l}\text { Weight } \\
\text { of CA } \\
(\mathrm{kg})\end{array}$ \\
\hline M30 & $0.45: 1: 1.562: 2.902$ & 183.0 & 406.81 & 635.4 & 1180.56 \\
\hline
\end{tabular}

\begin{tabular}{lllllll}
\multicolumn{7}{c}{ Table 1.1:Details of Materials for Large Size Beams } \\
\hline $\begin{array}{l}\text { Grade } \\
\text { of } \\
\begin{array}{l}\text { con- } \\
\text { crete }\end{array}\end{array}$ & $\begin{array}{l}\text { Size of } \\
\text { beam }\end{array}$ & $\begin{array}{l}\text { Notch } \\
\text { size } \\
(\mathrm{mm})\end{array}$ & $\begin{array}{l}\text { Water } \\
\text { wt } \\
(\mathrm{kg})\end{array}$ & $\begin{array}{l}\text { Cement } \\
\text { wt }(\mathrm{kg})\end{array}$ & $\begin{array}{l}\text { Weight } \\
\text { of FA } \\
(\mathrm{kg})\end{array}$ & $\begin{array}{l}\text { Weigh } \\
\text { t of } \\
\text { CA } \\
(\mathrm{kg})\end{array}$ \\
\hline & & 90 & & & & \\
M30 & $1000 * 300 *$ & $\begin{array}{l}120 \\
150\end{array}$ & 45.92 & 102.16 & 159.57 & 296.4 \\
& 75 & 180 & & & & \\
\hline
\end{tabular}

\begin{tabular}{lllllll}
\multicolumn{7}{c}{ Table 1.1:Details of Materials for Medium Size Beams } \\
\hline $\begin{array}{l}\text { Grade } \\
\text { of } \\
\begin{array}{l}\text { con- } \\
\text { crete }\end{array}\end{array}$ & $\begin{array}{l}\text { Size of } \\
\text { beam }\end{array}$ & $\begin{array}{l}\text { Notch } \\
\text { size } \\
(\mathrm{mm})\end{array}$ & $\begin{array}{l}\text { Water } \\
\text { wt } \\
(\mathrm{kg})\end{array}$ & $\begin{array}{l}\text { Cement } \\
\text { wt }(\mathrm{kg})\end{array}$ & $\begin{array}{l}\text { Weight } \\
\text { of FA } \\
(\mathrm{kg})\end{array}$ & $\begin{array}{l}\text { Weigh } \\
\text { t of } \\
\text { CA } \\
(\mathrm{kg})\end{array}$ \\
\hline & & 45 & & & & \\
M30 & $500 * 150 *$ & 75 & 11.50 & 25.56 & 39.98 & 74.17 \\
& 75 & 90 & & & & \\
\hline
\end{tabular}

\begin{tabular}{lllllll}
\multicolumn{7}{c}{ Table 1.2:Details of Materials for Small Size Beams } \\
\hline $\begin{array}{l}\text { Grade } \\
\text { of con- } \\
\text { crete }\end{array}$ & $\begin{array}{l}\text { Size of } \\
\text { beam }\end{array}$ & $\begin{array}{l}\text { Notch } \\
\text { size } \\
(\mathrm{mm})\end{array}$ & $\begin{array}{l}\text { Water } \\
\text { wt } \\
(\mathrm{kg})\end{array}$ & $\begin{array}{l}\text { Cement } \\
\text { wt }(\mathrm{kg})\end{array}$ & $\begin{array}{l}\text { Weight } \\
\text { of FA } \\
(\mathrm{kg})\end{array}$ & $\begin{array}{l}\text { Weight } \\
\text { of CA } \\
(\mathrm{kg})\end{array}$ \\
\hline M30 & 22.5 & & & & \\
& $250 * 75 * 75$ & $\begin{array}{l}30 \\
37.5\end{array}$ & 2.90 & 6.39 & 9.98 & 18.54 \\
& & & & & \\
\hline
\end{tabular}

\subsection{Test setup \& test procedure}

After 28days of curing the samples were taken out from the curing tank and kept for dry. Then notch is provided at one-third length of the beam with $\mathrm{a} / \mathrm{w}$ i.e., notch depth to specimen depth ratio of $0.3,0.4,0.5,0.6$. After this the sample was coated with white wash. One day later the sample was kept for testing.

\subsection{Test procedure for testing of specimens}
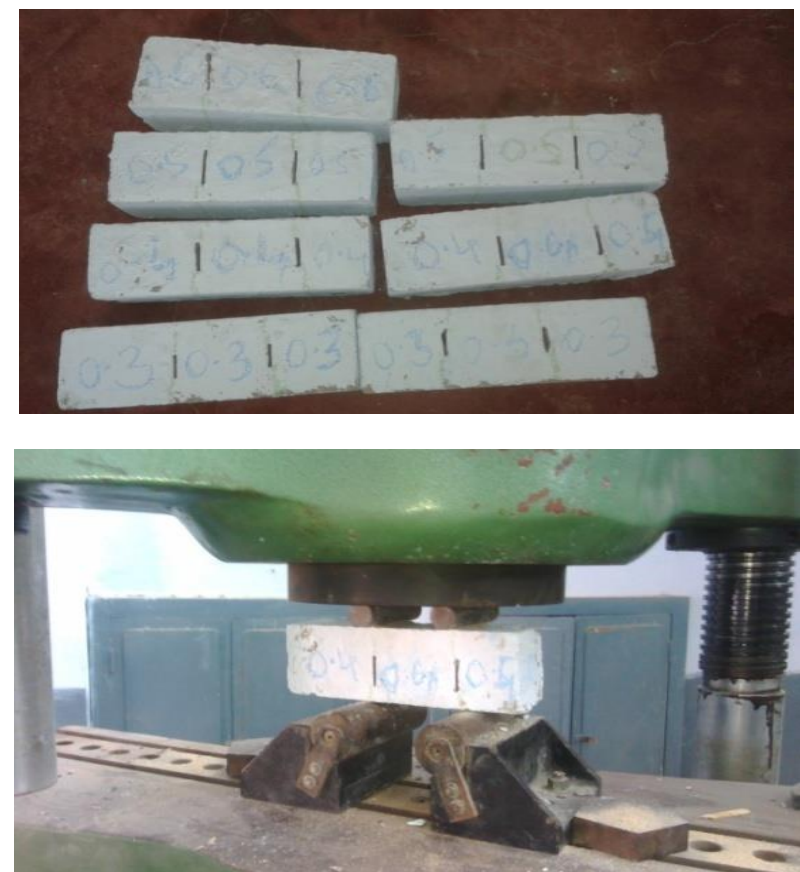

Fig. 1: Representing Small Size Beams. 

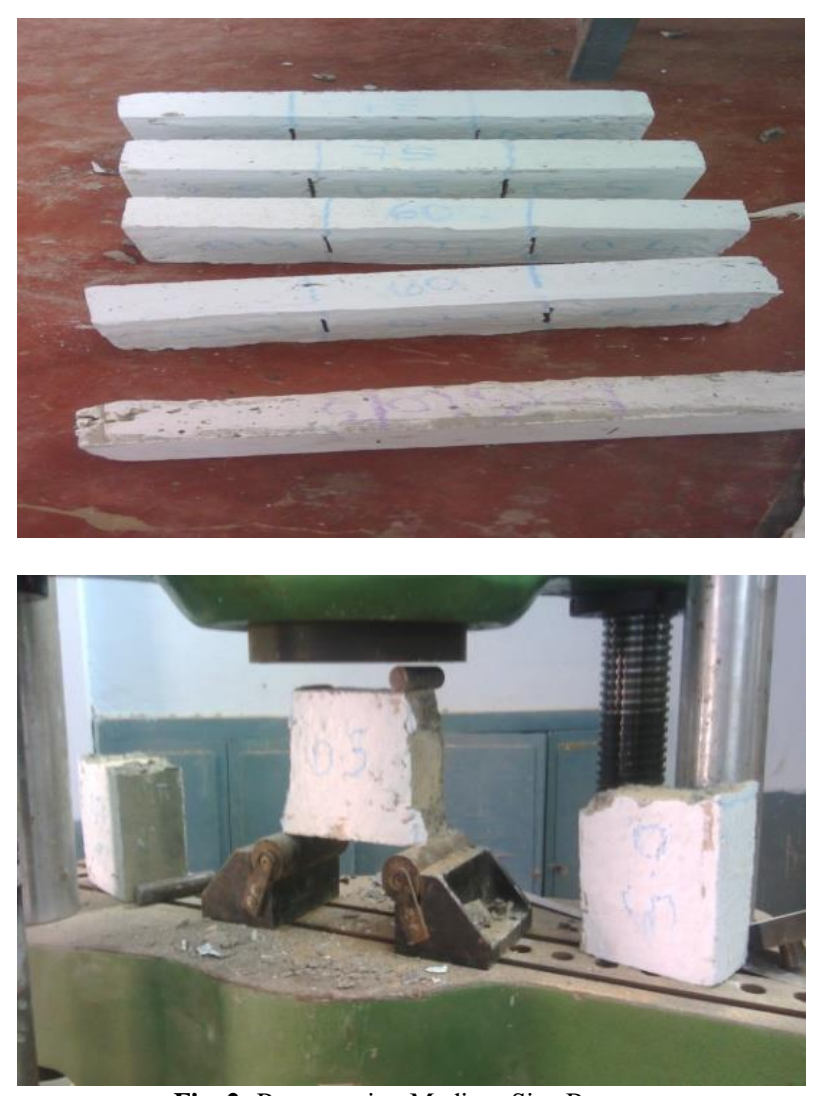

Fig. 2: Representing Medium Size Beams.
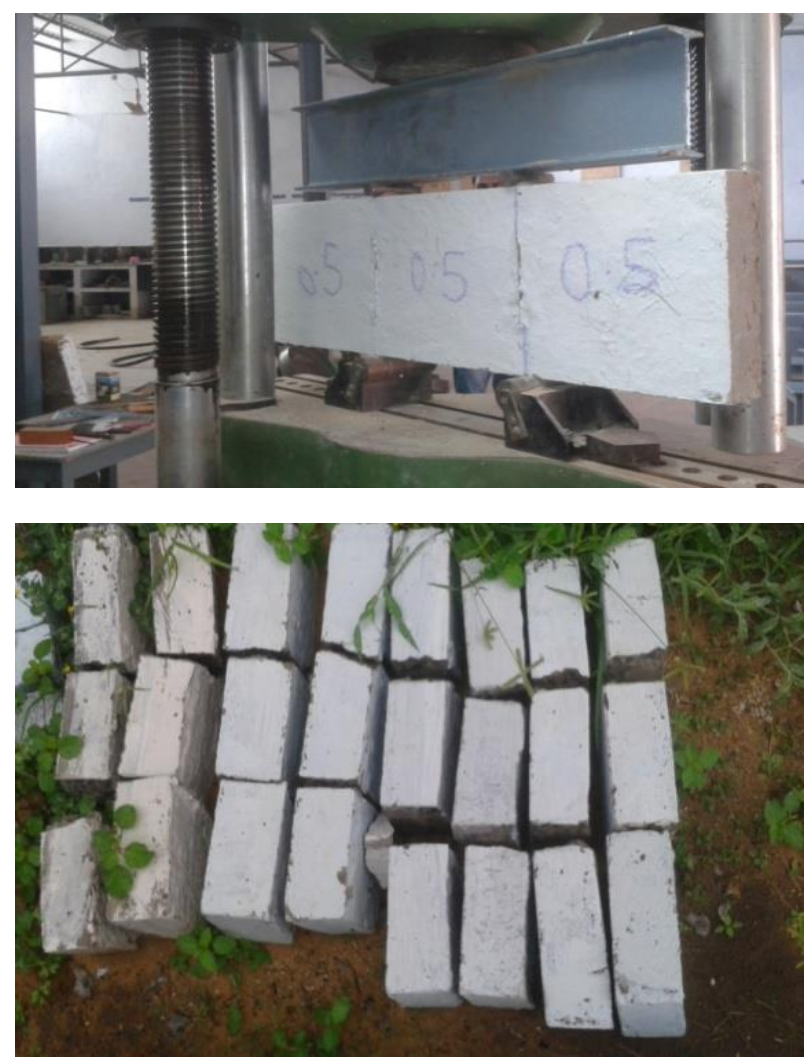

Fig. 3: Representing Large Size Beams.

\subsection{Size effect method (SEM)}

It may be noted that, the structural size effect is the most important illustration of fracture phenomena. Geometrically similar specimens of concrete as a quasi-brittle material, exhibit a pronounced size effect on their failure loads. Therefore, it is worthwhile to relate the size effect behavior to the fracture properties of materials. SEM has been developed according to effective elastic crack model originally proposed by Bazant and Pfeiffer. This method has been included in RILEM TC-89. In this method, major fracture parameters are evaluated by using three-point bending test on geometrically similar notched beams with varying sizes.

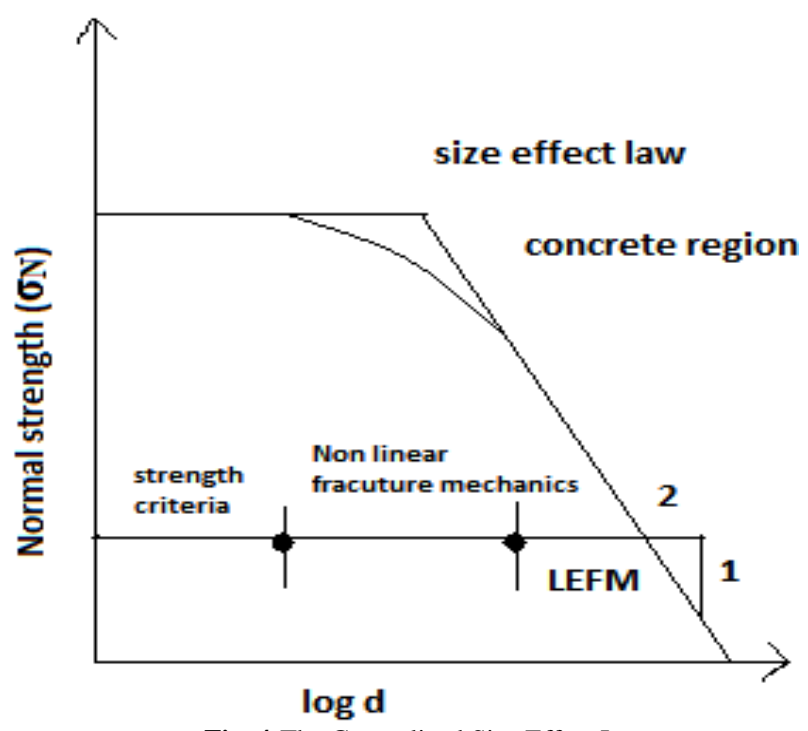

Fig. 4:The Generalized Size Effect Law.

\section{Methodology}

Mode-II fracture parameters in plain concrete for various sizes of beams with Doubly Centered Notch (DCN) are used to study the effect of stress intensity factor and fracture energy with various notch depth ratios with constant position of notch from center of beam.

For the calculation of the stress intensity factor the following formulae can be used for mode - II

$$
G_{I I}=\frac{\left(1-\mu^{2}\right) K_{I I}}{E}
$$

Where

$$
G_{I I}=\frac{W_{F S}}{A_{e f f}}
$$

$\mathrm{W}_{\mathrm{FS}}=$ work of fracture in mode II, calculates as the area under the load - slip curve.

$\mathrm{A}_{\mathrm{eff}}=\mathrm{effective}$ area of cross section of the specimen.

$\mu$ =poisons ratio for concrete $=0.3$.

$\mathrm{E}=$ young's modulus of the concrete.

Failure stresses for the beams $\tau_{n}=\frac{\text { ultimateload }}{2 * \text { (Breadthofnotch }) D}$

\section{Results and discussions}

The beam specimens were tested on the Universal Testing Machine under displacement rate control. All the beam specimens were tested under the four point loading under the displacement rate control. To understand the fracture behavior of plain concrete beams the following graphs were drawn, Load Vs displacement, stress intensity factor and fracture energy of the beams subjected to four point bending with double centered notch calculated. From the graphs and Tables it was observed that, for shear-mode failure of concrete, It was found that the stress intensity factor and fracture energy increasing with the increasing of beam sizes and decreasing the failure stresses with increasing the beam sizes. From 
the graphs we observe that the load decreases with increase of notch size.

\subsection{Failure stresses}

Table 1.4: Indicates the Ultimate Load Values and Shear Stress Values for Corresponding A/W Ratio of Different Sizes of Beams

\begin{tabular}{|c|c|c|c|c|}
\hline S.No & $\begin{array}{l}\text { Size of the } \\
\text { beam }\end{array}$ & $\begin{array}{l}\mathrm{a} / \mathrm{w} \\
\text { ratio }\end{array}$ & $\begin{array}{l}\text { Ultimate } \\
\operatorname{load}(\mathrm{KN})\end{array}$ & $\begin{array}{l}\text { Shear stress }\left(\tau_{N}\right. \\
) \mathrm{N} / \mathrm{mm}^{2}\end{array}$ \\
\hline \multirow{4}{*}{1} & \multirow{4}{*}{$250 * 75 * 75$} & 0.3 & 40.80 & 13.32 \\
\hline & & 0.4 & 37.50 & 13.61 \\
\hline & & 0.5 & 35.80 & 16.02 \\
\hline & & 0.6 & 32.70 & 18.42 \\
\hline \multirow{4}{*}{2} & \multirow{4}{*}{$500 * 150 * 75$} & 0.3 & 55.60 & 10.36 \\
\hline & & 0.4 & 53.50 & 11.11 \\
\hline & & 0.5 & 52.30 & 12.71 \\
\hline & & 0.6 & 42.30 & 14.53 \\
\hline \multirow{4}{*}{3} & \multirow{4}{*}{$1000 * 300 * 75$} & 0.3 & 209.55 & 7.06 \\
\hline & & 0.4 & 184.20 & 7.97 \\
\hline & & 0.5 & 180.10 & 9.29 \\
\hline & & 0.6 & 165.80 & 9.41 \\
\hline
\end{tabular}

From the above table it is observed that all sizes of beam at $a / w$ ratio of 0.3 , specimens take ultimate load but max shear stress is observed at $0.6 \mathrm{a} / \mathrm{w}$ ratio.

Table 1.5: Shows the Results of, Stress Intensity Factor and, Fracture Energy for Corresponding A/W Ratio of Different Sizes of Beams

\begin{tabular}{|c|c|c|c|c|}
\hline S.No & $\begin{array}{l}\text { Size of the } \\
\text { beam }\end{array}$ & $\begin{array}{l}\mathrm{a} / \mathrm{w} \\
\text { ratio }\end{array}$ & $\begin{array}{l}\text { Fracture ener- } \\
\text { gy }(\mathrm{G}) \mathrm{N} / \mathrm{mm}\end{array}$ & $\begin{array}{l}\text { Stress intensity } \\
\text { factor }(\mathrm{K}) \mathrm{N} / \mathrm{mm}^{2}\end{array}$ \\
\hline \multirow{4}{*}{1} & \multirow{4}{*}{$250 * 75 * 75$} & 0.3 & 6.87 & 424.51 \\
\hline & & 0.4 & 12.76 & 600.81 \\
\hline & & 0.5 & 8.67 & 490.94 \\
\hline & & 0.6 & 7.23 & 465.43 \\
\hline \multirow{4}{*}{2} & \multirow{4}{*}{$500 * 150 * 75$} & 0.3 & 14.72 & 600.8 \\
\hline & & 0.4 & 17.5 & 649.52 \\
\hline & & 0.5 & 12.60 & 615.71 \\
\hline & & 0.6 & 10.47 & 559.32 \\
\hline \multirow{4}{*}{3} & \multirow{4}{*}{$1000 * 300 * 75$} & 0.3 & 27.32 & 901.31 \\
\hline & & 0.4 & 28.33 & 917.85 \\
\hline & & 0.5 & 25.75 & 866.78 \\
\hline & & 0.6 & 24.21 & 849.03 \\
\hline
\end{tabular}

From the above table it is clear that all sizes of beam with $\mathrm{a} / \mathrm{w}$ ratio of 0.4 fracture energy and stress intensity factors are more when compared to all a/w ratio

\subsection{Graphs for load vs displacement}

For Small Size Beams:

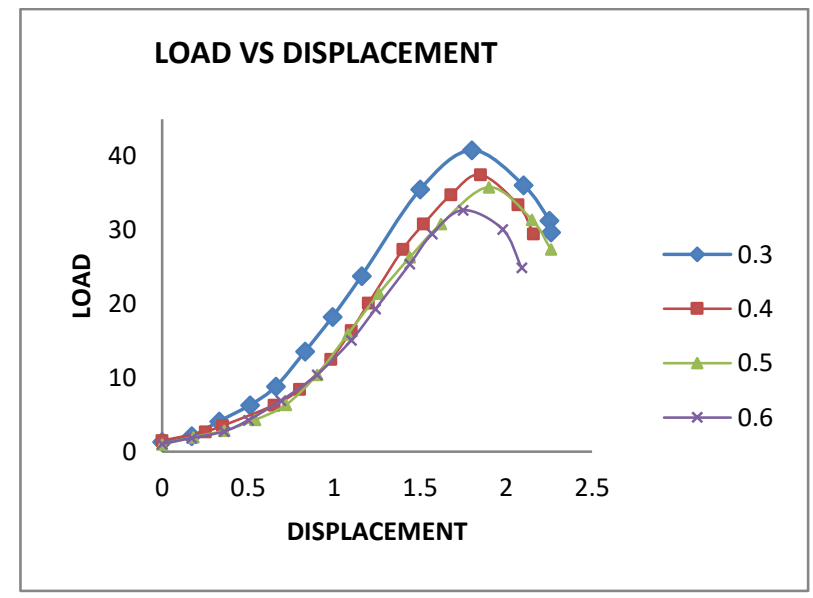

Graph. 1: Small Size Beams with All A/W Ratios.

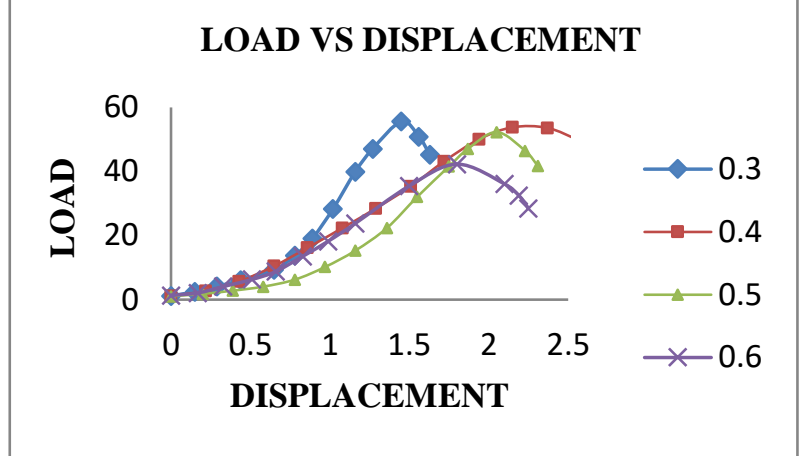

Graph. 2: Medium Size Beams with All A/W Ratios.

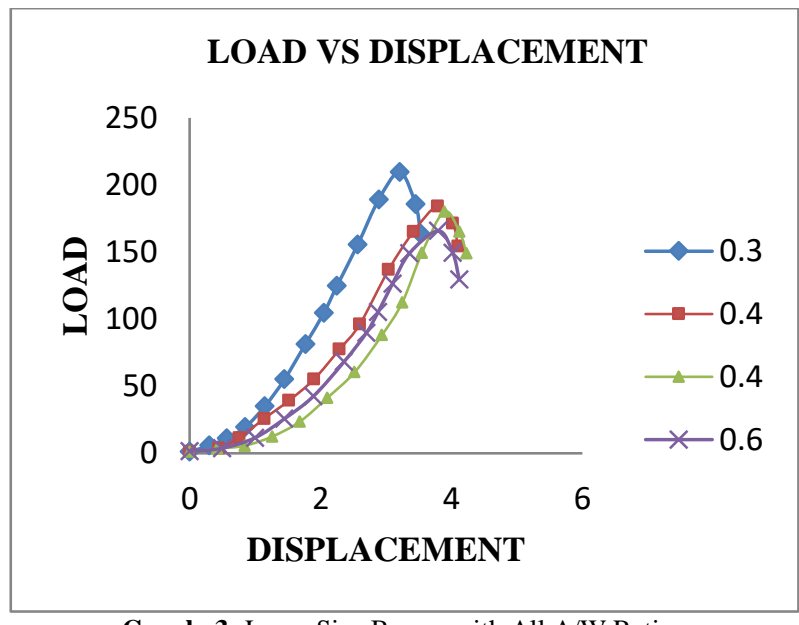

Graph. 3: Large Size Beams with All A/W Ratios.

Graphsfor fracture energy (G)vs. a/w ratio for all sizes of beams

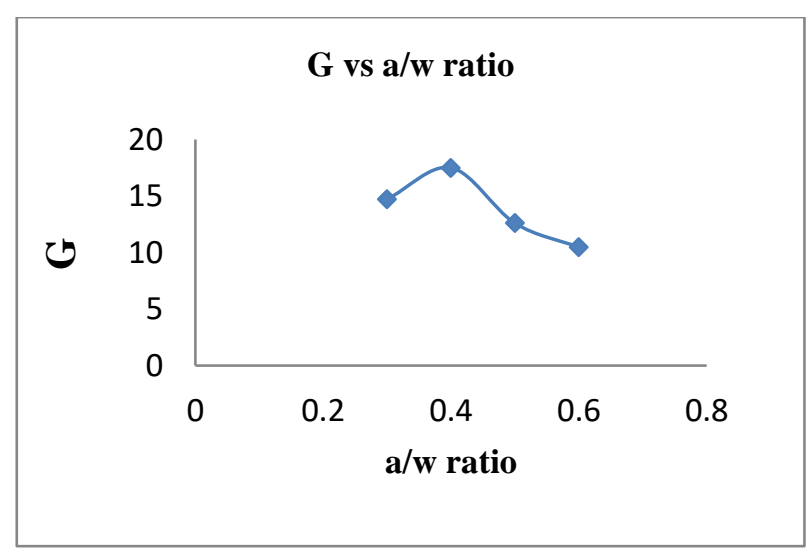

Graph. 4: Indicates G Vs. A/W Ratio of Small Size Beams.

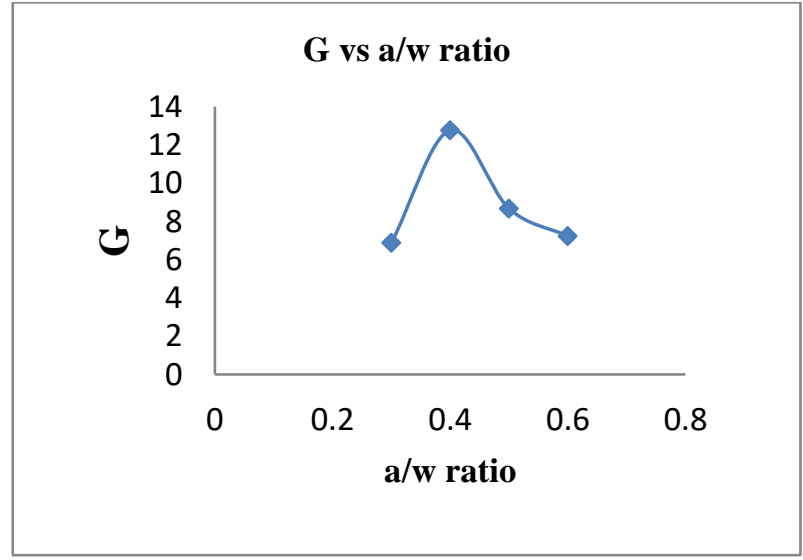

Graph. 5: Indicates G vs. A/W Ratio of Medium Size Beams. 


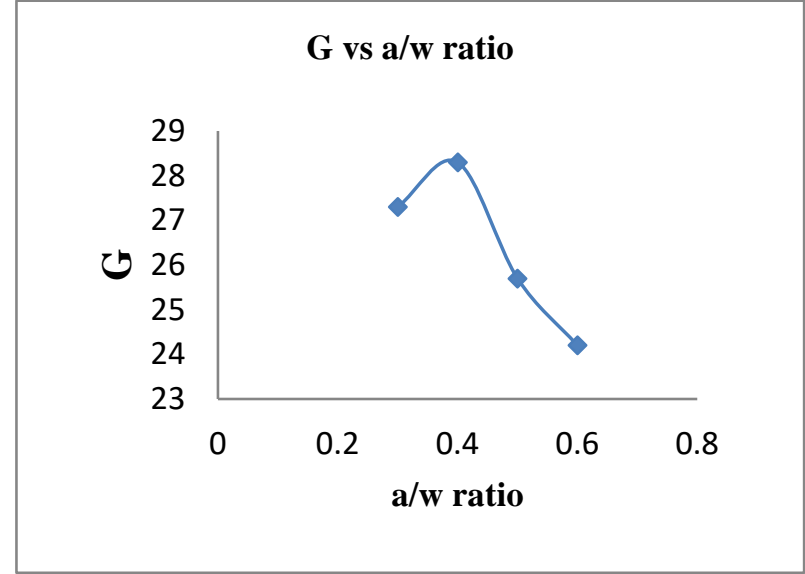

Graph. 6: Indicates G vs. A/W Ratio for Large Size Beams.

Graph for stress intensity factor (K) vs. a/w ratio of all sizes of beams.

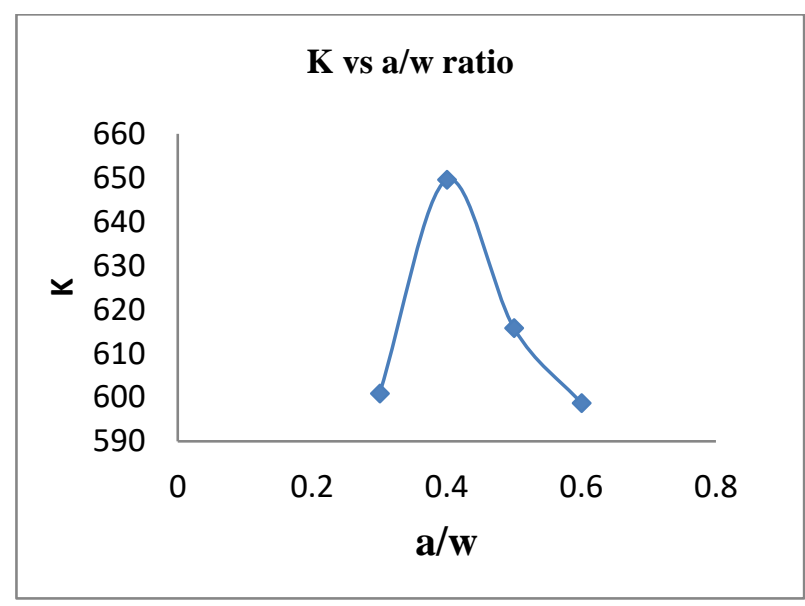

Graph. 7: Represents K vs. A/W Ratio for Small Size Beams.

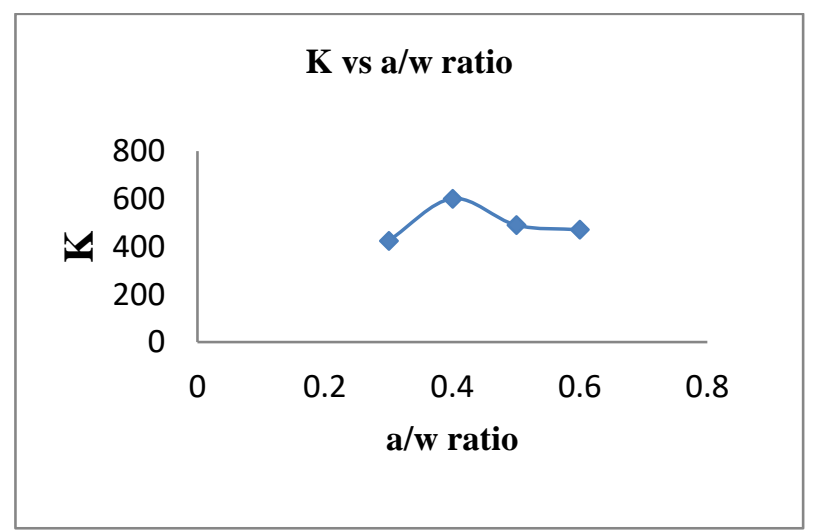

Graph. 8: Represents K vs. A/W Ratio for Medium Size Beams.

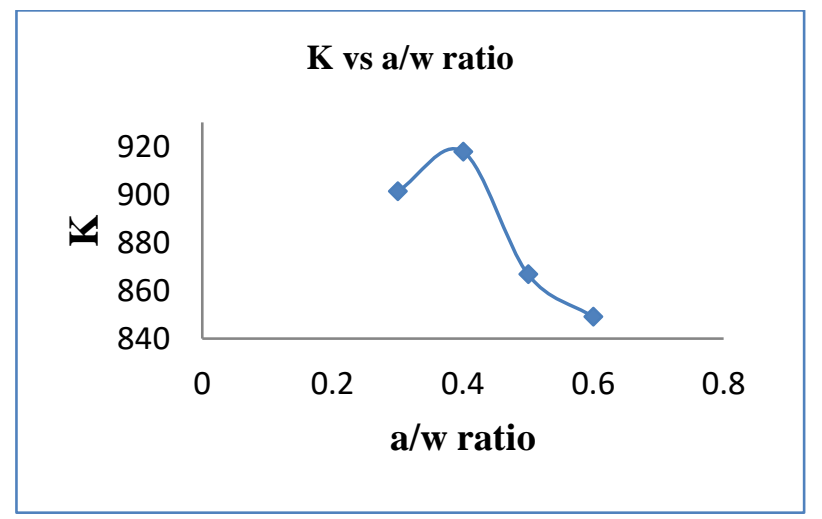

Graph. 9: Represents K vs. A/W Ratio for Large Size Beams.
Stress intensity factor especially in mode II, can be used as a crack propagation criterion. There is a critical value for stress intensity factor, required to propagate the crack. This critical value determined for mode II loading in plane strain is referred to critical fracture toughness $\left(\mathrm{K}_{\text {IIc }}\right.$ ).From the graphs it is observed that the stress intensity factor for the beams goes on increasing with increase in the constant notch to depth ratio.

\section{Conclusions}

Based on the tests on twenty four double centered notched concrete beam specimens, the following conclusions have been drawn

From results, we observe that the failure stresses decreases with increase in beam size.

- Fracture toughness or stress intensity factor increases from $0.3-0.4 \mathrm{a} / \mathrm{w}$ ratio and then decreases from $0.5-0.6 \mathrm{a} / \mathrm{w}$ ratio with increase in notch depth for all sizes of beams.

- Fracture energy or energy release rate increases from 0.3 $0.4 \mathrm{a} / \mathrm{w}$ ratio and then decreases from $0.5-0.6 \mathrm{a} / \mathrm{w}$ ratio with increase in notch depth for all sizes of beams.

- We observe that the load decreases with increase innotch size.

- Stress intensity factor increases with increase in beam size for constant notch to depth ratio.

- Fracture energy increases with increase in beam size for constant notch to depth ratio.

\section{References}

[1] Agarwal, B.D. and Giare, G.S., "Fracture toughness of short-fiber composites in Modes-I and II", Engineering Fracture Mechanics, Vol. 15, No. 1, 1981, pp.219-230. https://doi.org/10.1016/00137944(81)90119-3.

[2] BazantZ.,p, and Pfeiffer, P.A., "Shear fracture tests of concrete", materials and structures (RKLEM) , 1984, vol. 19, pp.111-121.

[3] Watkins, J. and Liu, K.L.W., "A Finite Element Study of Short Beam Test Specimens under Mode-II loading", The International Journal of Cement Composites and Light Weight Concrete, Vol.7, No.1, Feb.1985, pp.39-47. https://doi.org/10.1016/02625075(85)90025-9.

[4] Bazant, Z.,p, and Pfeiffer, P.A., "Tests on shear fracture and strain softening in concrete", proceedings of second symposium on interaction of Non-nuclear Munition with structures Florida, USA, April 1985, pp. 254-264.

[5] Davies, J., Yim, C.W.A and Morgan, T.G., "Determination of Fracture parameters of punch through shear specimens", The International Journal of Cement Composites and Light weight Concrete, Vol. 9, No. 1, Feb. 1987, pp. 33-41. https://doi.org/10.1016/02625075(87)90035-2.

[6] BhaskarDesai. V, "Some studies on Mode - II fracture and stress strain behavior in shear of cementitious materials", Ph.D thesis, Indian Institute of Science, Banglore".

[7] PrakashDesayi, Raghu Prasad .B.K, and BhaskarDesai. V, "Experimental determination of KIIc from compliance and fracture energy", proceedings national seminar on Aerostructures, organized by IIT, Kanpur, India, 29-30, Dec, 1993, pp. 33-34

[8] Prakashdesayi, B.K.Raghu Prasad and V.Bhaskar Desai, "Mode II fracture of cementitious materials- part - I: Studies on specimens of some new geometries", Journal of Structural Engineering, Vol.26, No.1, April 1999, pp.11-18.

[9] Prakashdesayi, B.K.Raghu Prasad and V.Bhaskar Desai, "Mode II fracture of cementitious materials- part - II: Fracture toughness of cement paste, mortar, concrete and no-fines concrete.Journal of structural engg Vol. 26, No. 1, April 1999, pp. 19-27.

[10] Prakashdesayi, B.K.Raghu Prasad and V.Bhaskar Desai, conducted Mode-II fracture of cementitious materials- part-IV: Fracture toughness, shear strength and slip of fiber reinforced cement mortar and concrete.Journal of structural engg. Vol. 26, No. 4, Jan 2000, pp. 267-273.

[11] Prakashdesayi, B.K.Raghu Prasad and V.Bhaskar Desai, conducted Mode-II fracture of cementitious materials- part-V: Size effect on fracture toughness shear strength and slip of cement mortar and 
concrete reinforced with and without fibers.Journal of structural engg, Vol, 27, No. 2, July 2000, pp.99-104

[12] Owens, P.L. (1993). "Light weight aggregates for structural concrete," Structural Light weight Aggregate Concrete, Chapman \& Hall, London, pp.1-18.

[13] ChiJM,Huang,R,Yang,C.C,andChang.J.J,'Effect of aggregate properties on the strength and stiffness of light weight concrete".Cement\& Concrete Composites 2003. https://doi.org/10.1016/S0958-9465(02)00020-3.

[14] L. Cavaleri N. Miraglia and M. Papia, "Pumice Concrete for structural wall panels", Engineering structures, Vol. 25, No. 1,Jan 2003 , pp. 115-125. https://doi.org/10.1016/S0141-0296(02)00123-2.

[15] Dr. V. Bhaskar Desai, Dr.BLP.Swamy N. Sivalingarao, "A Brief study on strength properties of partially replaced emery stone aggregate concrete with the partial replacement of cement by double blended admixtures", Research journal of Engineering and Tech, January-March 2011, vol.4, No.1.

[16] Bazant, Z.P., and Kazemi, M.T.’Determination of Fracture Energy Process Zone Length and Brittleness Number from Size Effect, with Application to Rock and Concrete", Journal of Fracture, 44 111-131.

[17] Griffith, A.A. 1921. The Phenomenon of Rupture and Flow in Solids, Philosophical Transactions of Royal Society of London, A221: 163-197.https://doi.org/10.1098/rsta.1921.0006.

[18] Iosipescu, N., 1967. New Accurate Procedure for Single Shear Testing of Metals, Jl. of Materials, 2: 537-566. 